I nvest i gat i on of mol ecul ar mechani sms of mel ting and crystal I izati on of i sot actic pol ypropyl ene by i n si tu Raman spect roscopy

\begin{tabular}{|l|l|}
\hline 著者 & H ej i ma Yusuke, Takeda Kent o, Ni t t a Koh- hei \\
\hline 著者別表示 & 比江嶋 祐介, 新田 晃平 \\
\hline $\begin{array}{l}\text { j our nal or } \\
\text { publ i cat i on ti tl e }\end{array}$ & Necr onml ecul es \\
\hline vol une & 50 \\
\hline number & 15 \\
\hline page range & $5867-5876$ \\
\hline year & $2017-08$-01 \\
\hline URL & ht t p: //doi . or g/10. 24517/00050382 \\
\hline
\end{tabular}

doi: 10.1021/acs.macromol.7b00229 


\section{Investigation of the molecular mechanisms of melting and crystallization of isotactic polypropylene by in situ Raman spectroscopy}

Yusuke Hiejima, Kento Takeda, and Koh-hei Nitta*

Department of Chemical and Materials Science, Kanazawa University, Kakuma Campus, Kanazawa 920-1192, Japan

\section{ABSTRACT}

In situ Raman spectroscopy has been used to reveal the molecular behavior of isotactic polypropylene during melting and crystallization. The $400 \mathrm{~cm}^{-1}$ band assigned to C-C-C bending shows a blue shift during heating, suggesting an increase in conformational disorder, whereas the $1330 \mathrm{~cm}^{-1}$ band assigned to $\mathrm{CH}_{2}$ twisting shows a red shift owing to an increase in the interchain distance. We suggest that interchain expansion proceeds even in the melt state, while the chain conformation becomes sufficiently disordered at the melting point. During the cooling process, the peak shifts at given temperatures are essentially the same as those during heating, except for the supercooled region where the peak shifts show obvious hystereses. By extrapolating the linear correlation between the peak shift of the $400 \mathrm{~cm}^{-1}$ band and the characteristic length along the chain axis, the critical stem size for crystallization is estimated to be $\sim 2.4 \mathrm{~nm}$. 


\section{INTRODUCTION}

Isotactic polypropylene (iPP) is a typical semicrystalline polymer, and it is ubiquitously used for a variety of daily commodities. The crystalline structures and superstructures that govern the mechanical properties of polymeric solids are spontaneously formed during the cooling process from the melt. The crystallization and melting behaviors of iPP have long been investigated by various methods, such as differential scanning calorimetry (DSC) and polarized optical microscopic observations, and the mechanisms of crystal growth have been proposed. ${ }^{1-8}$ Recent in situ X-ray experiments have revealed the crystallization behavior at the mesoscopic scale, such as the kinetics of the disappearance of the crystalline lattice ${ }^{9}$ and domain formation of the lamellar precursor during crystallization. ${ }^{10-12}$ The growth front of spherulites has been investigated by combining microscopic X-ray and infrared (IR) spectroscopy, and the radial growth of lamellar crystals has been directly observed in situ. ${ }^{13}$

Vibrational spectroscopy is advantageous for molecular investigation of melting and crystallization mechanisms because it is sensitive to changes in the microstructure of polymers and/or conformation of polymer chains. The temperature dependence of the Raman peak shifts for iPP and polyethylene terephthalate (PET) have been investigated, and the shifts can be interpreted by thermal expansion of the unit cell. ${ }^{14,15}$ The increase in the number of trans chains of polyethylene in the cooling process has been monitored in situ by the C-C stretching modes. ${ }^{16}$ Raman spectroscopy of iPP has been used to determine the crystallinity ${ }^{17-19}$ and the length of the helical sequences. ${ }^{20-22}$ Low-frequency Raman spectroscopy below $\sim 100 \mathrm{~cm}^{-1}$ has also been used to characterize the changes in the lamellar crystalline structure of semicrystalline polymers. It has been found that the frequency of the longitudinal acoustic mode (LAM) around $10 \mathrm{~cm}^{-1}$ is 
sensitive to the lamellar thickness and long period. ${ }^{23-25}$ According to observation of the LAM, rod-like structures (length $\sim 10 \mathrm{~nm}$ ) consisting of helical chains form in glassy iPP. ${ }^{26}$ It has been suggested that the conformational changes of iPP can be detected by the $400 \mathrm{~cm}^{-1}$ band assigned to the $\mathrm{C}-\mathrm{C}-\mathrm{C}$ bending mode. ${ }^{27,28}$ The intensity of the $400 \mathrm{~cm}^{-1}$ band decreases during melting, which can be explained by reduction of the sequence length of the helical chains. ${ }^{19}$

It is well known that iPP shows polymorphism ( $\alpha, \beta, \gamma$, and mesomorphic forms) depending on the crystallization conditions and additives. ${ }^{29-34}$ The monoclinic $\alpha$ form, which is composed of $3_{1}$ helical chains of iPP, is commonly observed when cooling from the melt. ${ }^{35,36}$ Several regularity bands have been reported, which correspond to a specific number $(n)$ of monomeric units forming helical chains. ${ }^{20-22}$ IR spectroscopy has revealed that short helical chains $(n \leq 10)$ persist even above the melting temperature, and the length and number of the chains gradually decrease with increasing temperature. ${ }^{37-40}$ The critical number of monomeric units at the onset of the crystallization of iPP is $12(n=12)^{37}$ according to Raman spectroscopic observation. ${ }^{15}$

In this work, in situ Raman spectroscopy is used to investigate the molecular aspects of the melting and crystallization processes of iPP. The temperature dependences of the crystallinity and the intensity of the regularity bands are evaluated. The peak shifts of the 400 and $1330 \mathrm{~cm}^{-1}$ bands are related to the structural changes in the directions parallel and perpendicular to the molecular chain axis in the solid phase. The molecular mechanisms of melting and crystallization of iPP are discussed by extrapolating these correlations to the melt state. 


\section{EXPERIMENTAL SECTION}

Pellets of iPP $\left(M_{\mathrm{w}}=56 \times 10^{4}, M_{\mathrm{w}} / M_{\mathrm{n}}=5.8\right)$ were provided by Japan Polychem Corporation (Yokkachi, Japan). The iPP pellets ( 2 g) were dissolved in $120 \mathrm{~mL}$ of xylene and then precipitated in $2 \mathrm{~L}$ of methanol three times to remove additives that would act as nucleation agents. The iPP samples were dried in an oven at $120^{\circ} \mathrm{C}$ for $12 \mathrm{~h}$. The additive-free iPP was melted in a laboratory hot press for $5 \mathrm{~min}$ at $230{ }^{\circ} \mathrm{C}$ and $20 \mathrm{MPa}$. It was then quenched in boiled water to prepare a sheet with a thickness of about $1 \mathrm{~mm}$ or $100 \mu \mathrm{m}$. For comparison, an iPP sample with lower molecular weight $\left(M_{\mathrm{w}}=22 \times 10^{4}, M_{\mathrm{w}} / M_{\mathrm{n}}=4.2\right)$ was also prepared using the same procedure.

The DSC measurements were performed with a Perkin-Elmer Diamond differential scanning calorimeter. A portion of the sample ( $3 \mathrm{mg}$ ) was cut out of the $100 \mu \mathrm{m}$ thick sheet and packed in an aluminum pan. The pan was heated from 25 to $230{ }^{\circ} \mathrm{C}$ at a rate of 2 or $15^{\circ} \mathrm{C} / \mathrm{min}$ in a nitrogen atmosphere. The sample was maintained at $230{ }^{\circ} \mathrm{C}$ for $10 \mathrm{~min}$ before cooling to $25^{\circ} \mathrm{C}$ at the same rate used for heating. The crystallinity $\chi_{\mathrm{DSC}}(T)$ at a given temperature $T$ was determined with the following equation:

$$
\chi_{\mathrm{Dsc}}(T)=\frac{\Delta H(T)}{\Delta H_{\text {total }}}
$$

where $\Delta H(T)$ and $\Delta H_{\text {total }}$ are the enthalpies of the melting or crystallization transitions integrated to temperature $T$ and over the entire transition, respectively. The relative crystallinity $\bar{\chi}_{\mathrm{Dsc}}(T)$ was determined by normalizing by the value at room temperature. 
The apparatus used for in situ Raman spectroscopy is shown schematically in Fig. 1. A hot stage (FP-82, Mettler Toledo) was installed in the Raman spectroscopic apparatus developed in our laboratory. ${ }^{41}$ Laser light from a DPSS laser (LASOS, Jena, Germany) with a wavelength of $637.9 \mathrm{~nm}$ and laser power of $200 \mathrm{~mW}$ was irradiated into a $1 \mathrm{~cm}$ square specimen cut out of the additive-free iPP sheet ( $\sim$ mm thick) and placed between two cover glasses. The backwardscattered light was detected by a charge-coupled device (CCD) camera equipped with a monochromator (PIXIS 100 and SpectraPro 2300i, Princeton Instruments, Trenton, NJ, USA). The sample temperature was controlled with the hot stage, where the temporal change of the sample temperature was set to be the same as that of the DSC measurements. The Raman spectra were accumulated 50 times with an exposure time of $1 \mathrm{~s}$.

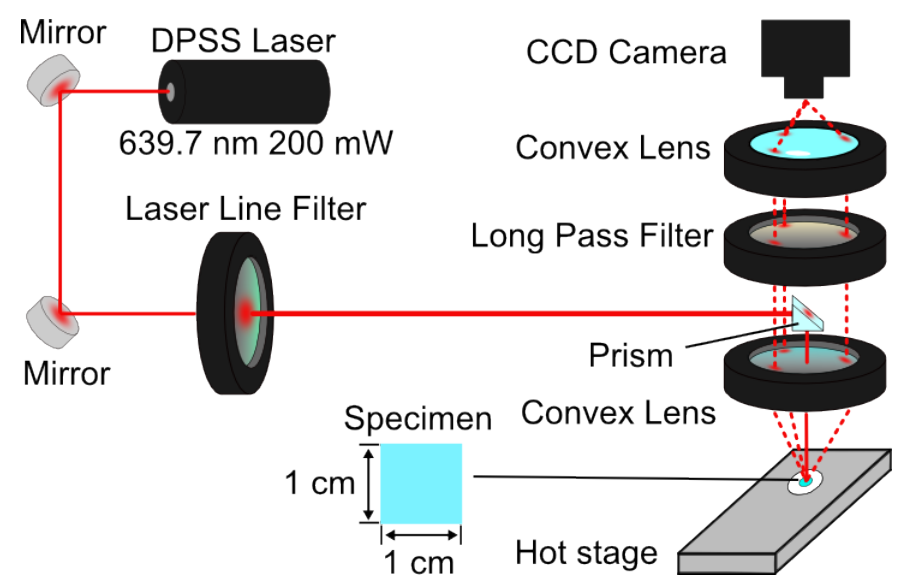

Figure 1. Schematic illustration of the experimental system used for in situ Raman spectroscopy.

Typical Raman spectra of iPP in the solid and melt states are shown in Fig. 2. The assignments of the Raman bands of iPP are given in Table 1 . The regularity bands at 973, 998, 841 , and $1220 \mathrm{~cm}^{-1}$ are assigned to the helical chains of 5, 10,12, 14 monomeric units, respectively. ${ }^{20-22}$ The $973 \mathrm{~cm}^{-1}$ band is used as the internal reference. ${ }^{21,42,43}$ While many of the 
bands assigned to the crystalline chains disappear upon melting, Raman bands assigned to the amorphous chains, such as the $\mathrm{C}-\mathrm{C}$ stretching modes at $830 \mathrm{~cm}^{-1}$, are clearly observed in the melt state. The 400 and $1330 \mathrm{~cm}^{-1}$ bands in the spectra of both the solid and melt states are assigned to the $\mathrm{C}-\mathrm{C}-\mathrm{C}$ bending and $\mathrm{CH}_{2}$ twisting modes, respectively. ${ }^{44}$

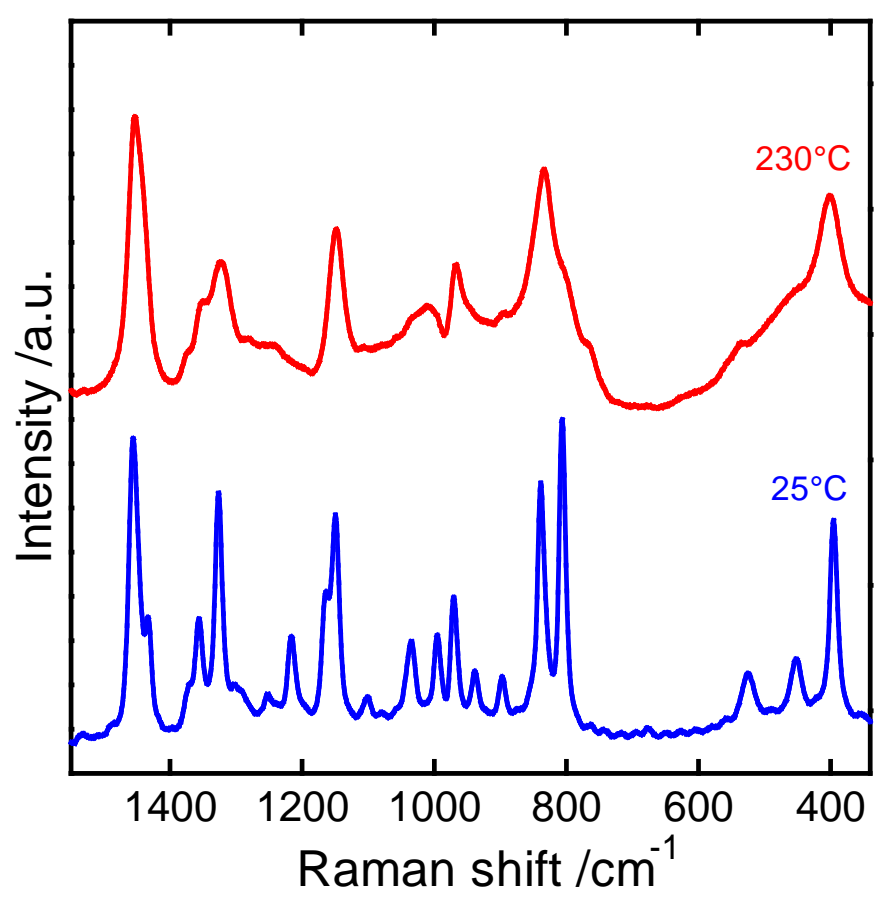

Figure 2. Raman spectra of iPP at 25 and $230^{\circ} \mathrm{C}$. 
Table 1. Vibrational and phase assignment of the Raman spectrum of iPP. ${ }^{20-22,44}$

\begin{tabular}{|c|c|c|}
\hline Raman shift $/ \mathrm{cm}^{-1}$ & Mode & Phase \\
\hline 400 & C-C-C bending, $\mathrm{CH}$ bending & - \\
\hline 809 & $\mathrm{CH}_{2}$ rocking, $\mathrm{C}-\mathrm{CH}_{3}$ stretching, $\mathrm{C}-\mathrm{C}$ stretching & Helical chain \\
\hline 830 & $\mathrm{C}-\mathrm{CH}_{3}$ stretching, $\mathrm{C}-\mathrm{C}$ stretching, $\mathrm{CH}_{3}$ rocking & Amorphous \\
\hline 841 & $\mathrm{CH}_{2}$ rocking, $\mathrm{C}-\mathrm{CH}_{3}$ stretching & Helical chain (12 monomer unit) \\
\hline 973 & $\mathrm{CH}$ bending, $\mathrm{C}-\mathrm{C}$ stretching & Helical chain (5 monomer unit) \\
\hline 998 & $\mathrm{CH}_{3}$ rocking, $\mathrm{CH}$ bending & Helical chain (10 monomer unit) \\
\hline 1220 & $\mathrm{CH}_{2}$ twisting, $\mathrm{C}-\mathrm{CH}_{3}$ stretching, $\mathrm{CH}$ bending & Helical chain (14 monomer unit) \\
\hline 1330 & $\mathrm{CH}$ bending, $\mathrm{CH}_{2}$ twisting & - \\
\hline
\end{tabular}

As shown in Fig. 3, each Raman band can be successfully fitted by the sum of Voigt functions, except for the 830 and $841 \mathrm{~cm}^{-1}$ bands (Fig. 3(b)). The three Raman bands at 808, 830, and $841 \mathrm{~cm}^{-1}$ were fitted by the sum of two Voigt functions, because the $830 \mathrm{~cm}^{-1}$ band is observed as a shoulder of the strong $841 \mathrm{~cm}^{-1}$ band. The intensity of the $808 \mathrm{~cm}^{-1}$ band was used to determine the crystallinity of iPP by dividing the intensity of this band by the sum of the intensities of the three bands at 808,830 , and $841 \mathrm{~cm}^{-1}:{ }^{17}$

$$
\chi_{\text {Raman }}(T)=\frac{I_{808}}{I_{808}+I_{830+841}}
$$

The relative crystallinity $\bar{\chi}_{\text {Raman }}(T)$ at given temperature $T$ was determined by normalizing by the value at a sufficiently low temperature where the crystallinity is sufficiently high:

$$
\bar{\chi}_{\text {Raman }}(T)=\frac{\chi_{\text {Raman }}(T)}{\chi_{\text {Raman }}^{0}},
$$


where $\chi^{0}$ Raman is the crystallinity at room temperature. The relative intensities of the regularity bands ${ }^{20-22}$ were determined by dividing the intensities of the 998 and $1220 \mathrm{~cm}^{-1}$ bands by that of the internal reference band at $973 \mathrm{~cm}^{-1}$. The peak shift $\Delta v(T)$ was defined by the deviation of the peak position from that at room temperature:

$$
\Delta v(T)=v(T)-v_{0},
$$

where $v(T)$ and $v_{0}$ are the peak positions of the Raman band at temperature $T$ and room temperature, respectively.
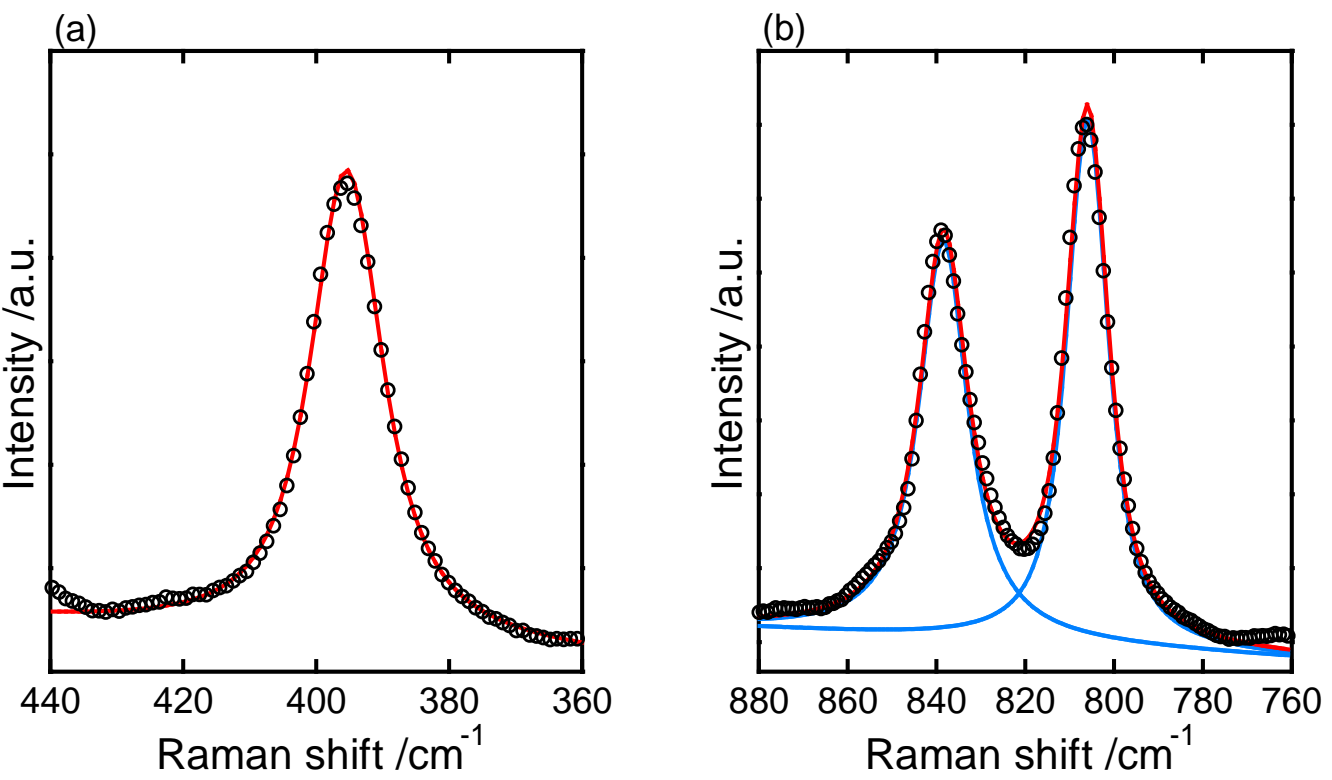

Figure 3. Raman spectrum of iPP at room temperature (circles). The red lines represent fitting by the sum of Voigt functions (blue lines).

Wide-angle X-ray diffraction (WAXD) measurements were performed with an X-ray diffractometer (D8 Discover, Bruker) with $\mathrm{Cu} \mathrm{K} \alpha$ radiation. For the WAXD measurements at high temperatures, we used a sample holder composed of an aluminum body equipped with a set 
of cartridge heaters and a thermocouple. The temperature was maintained at each temperature for 10 min before the measurement. The two-dimensional WAXD patterns were collected with an exposure time of 5 min and the one-dimensional profiles were obtained by integration over the azimuthal angles. The lattice plane distance $d_{h k l}$ was calculated by the Bragg equation:

$$
d_{h k l}=\frac{\lambda}{2 \sin \theta}
$$

where $\lambda(=1.54 \AA)$ is the wavelength of the $\mathrm{X}$-ray and $\theta$ is the diffraction angle. For the monoclinic crystal form, the lattice constants were calculated with the following equation: ${ }^{45}$

$$
\frac{1}{d_{h l}^{2}}=\frac{1}{\sin ^{2} \beta}\left(\frac{h^{2}}{a^{2}}+\frac{k^{2} \sin ^{2} \beta}{b^{2}}+\frac{l^{2}}{c^{2}}-\frac{2 h l \cos \beta}{a c}\right)
$$

where $a, b, c$, and $\beta$ are the lattice constants of the monoclinic iPP crystal. Raman spectra were also measured with the same setup used for the WAXD measurements to compare the lattice constants and Raman shifts at high temperatures.

\section{RESULTS AND DISCUSSION}

The relative crystallinities of iPP during heating and cooling determined by DSC and Raman spectroscopy are compared in Fig. 4. During heating, $\bar{\chi}_{\mathrm{Dsc}}(T)$ remains at one until about $130{ }^{\circ} \mathrm{C}$ followed by a rapid decrease to zero at the melting point of $167{ }^{\circ} \mathrm{C}$. In contrast, $\bar{\chi}_{\text {Raman }}(T)$ shows a gradual decrease with increasing temperature above $100{ }^{\circ} \mathrm{C}$, reflecting the onset of structural fluctuations at the molecular level owing to thermal agitation. At the melting point, $\bar{\chi}_{\text {Raman }}(T)$ decreases to zero, in accordance with $\bar{\chi}_{\text {Dsc }}(T)$. In the cooling process, both 
$\bar{\chi}_{\text {DSC }}(T)$ and $\bar{\chi}_{\text {Raman }}(T)$ show abrupt increases at $130{ }^{\circ} \mathrm{C}$. While $\bar{\chi}_{\text {Dsc }}(T)$ immediately reaches one at $122{ }^{\circ} \mathrm{C}, \bar{\chi}_{\text {Raman }}(T)$ gradually increases with decreasing temperature, suggesting that microscopic reorganization of the molecular chains occurs even in the solid state. The crystallinities determined by various methods are generally in good agreement, although they are not identical. ${ }^{46}$ It has been recently reported that IR spectroscopy detects the molecular structural changes in PET while the DSC curve shows no obvious changes. ${ }^{47}$ This indicates that in situ Raman spectroscopy makes it possible to detect molecular reorganization that is undetectable by thermal analysis.
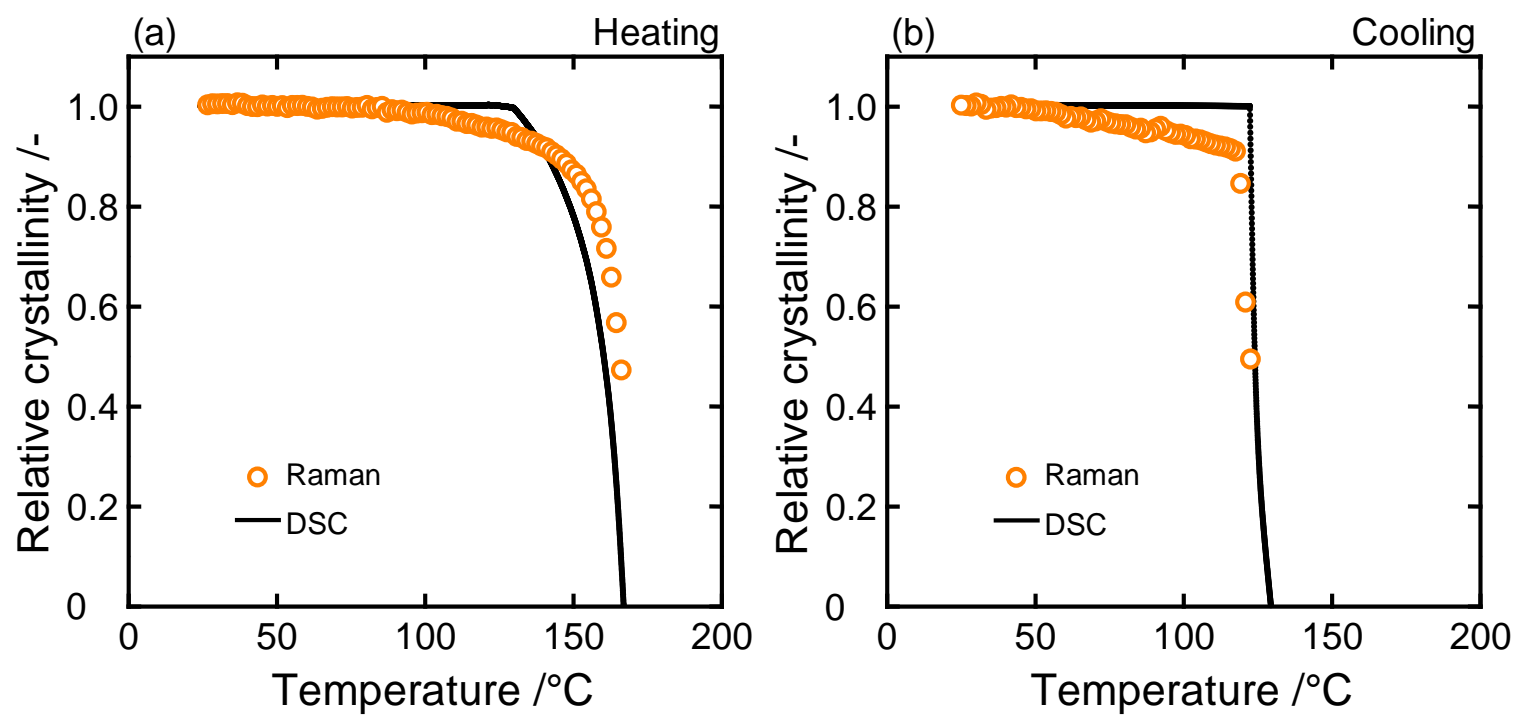

Figure 4. Temperature dependence of the relative crystallinity estimated by DSC and Raman spectroscopy under (a) heating and (b) cooling processes at heating/cooling rates of $\pm 2{ }^{\circ} \mathrm{C} / \mathrm{min}$.

In situ Raman spectra of iPP in the regions of the 1000 and $1220 \mathrm{~cm}^{-1}$ bands during heating from 30 to $225{ }^{\circ} \mathrm{C}$ at $5{ }^{\circ} \mathrm{C}$ intervals are shown in Fig. 5. The intensities of these two regularity bands gradually decrease with increasing temperature, and they sharply decreases upon melting. 
The $1220 \mathrm{~cm}^{-1}$ band disappears in the melt state, while the $998 \mathrm{~cm}^{-1}$ band merges with the nearby $1030 \mathrm{~cm}^{-1}$ band and persists as a broad band at $\sim 1100 \mathrm{~cm}^{-1}$. Although quantitative analysis of the $998 \mathrm{~cm}^{-1}$ band in the melt is difficult, the persistence of the $998 \mathrm{~cm}^{-1}$ band suggests the existence of helical chains up to $n=10$ in the melt state, which is consistent with an IR study. ${ }^{40}$ Fig. 6 shows the temperature dependence of the relative intensities of the regularity bands at 998 and $1220 \mathrm{~cm}^{-1}$, which correspond to helical chains with monomeric units of $n=10$ and $14,{ }^{20-22}$ respectively. In the heating process, the relative intensities of the regularity bands decrease with increasing temperature, suggesting a decrease of the length of the helical sequences. The slope becomes steeper above $100{ }^{\circ} \mathrm{C}$, which is consistent with the decrease of $\bar{\chi}_{\text {Raman }}(T)$. The relative intensities of these regularity bands sharply decrease at the melting temperature, and the $1220 \mathrm{~cm}^{-1}$ band completely disappears above the melting temperature. In the cooling process, both the 998 and $1220 \mathrm{~cm}^{-1}$ bands show a drastic increase at $122{ }^{\circ} \mathrm{C}$, indicating rapid growth of the helical structure at the crystallization temperature followed by a gradual increase of the helical sequences with decreasing temperature in the solid phase, which has also been found by IR spectroscopy. ${ }^{15,37}$ 
(a)

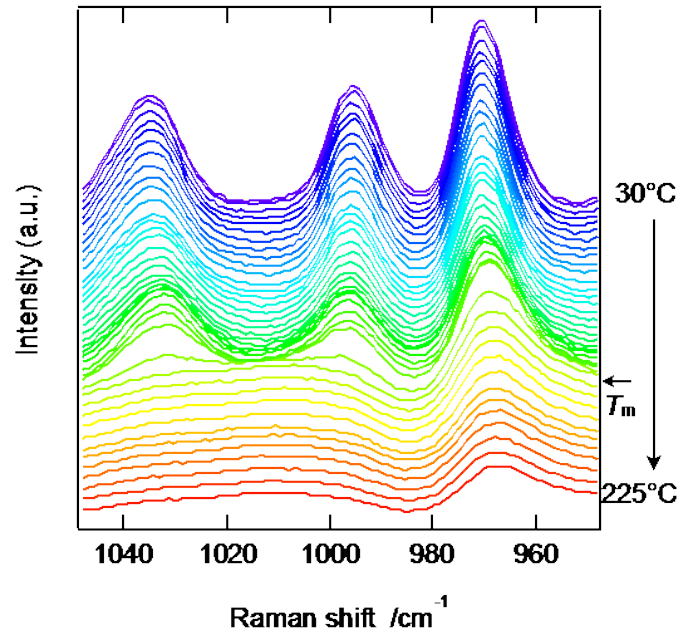

(b)

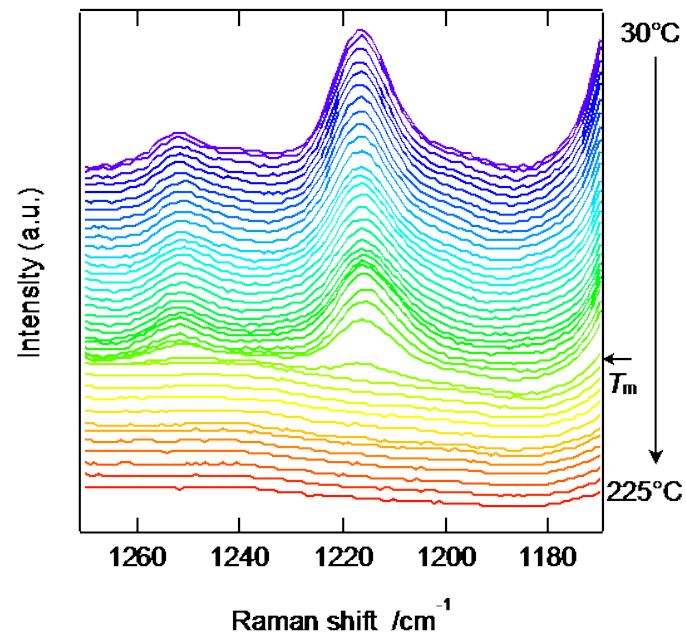

Figure 5. In situ Raman spectra of iPP in the (a) 1000 and (b) $1220 \mathrm{~cm}^{-1}$ regions at temperatures from 30 to $225{ }^{\circ} \mathrm{C}$ (from top to bottom) at $5{ }^{\circ} \mathrm{C}$ intervals during heating at a rate of $2{ }^{\circ} \mathrm{C} / \mathrm{min}$. The melting temperature $T_{\mathrm{m}}$ is indicated by the arrows.
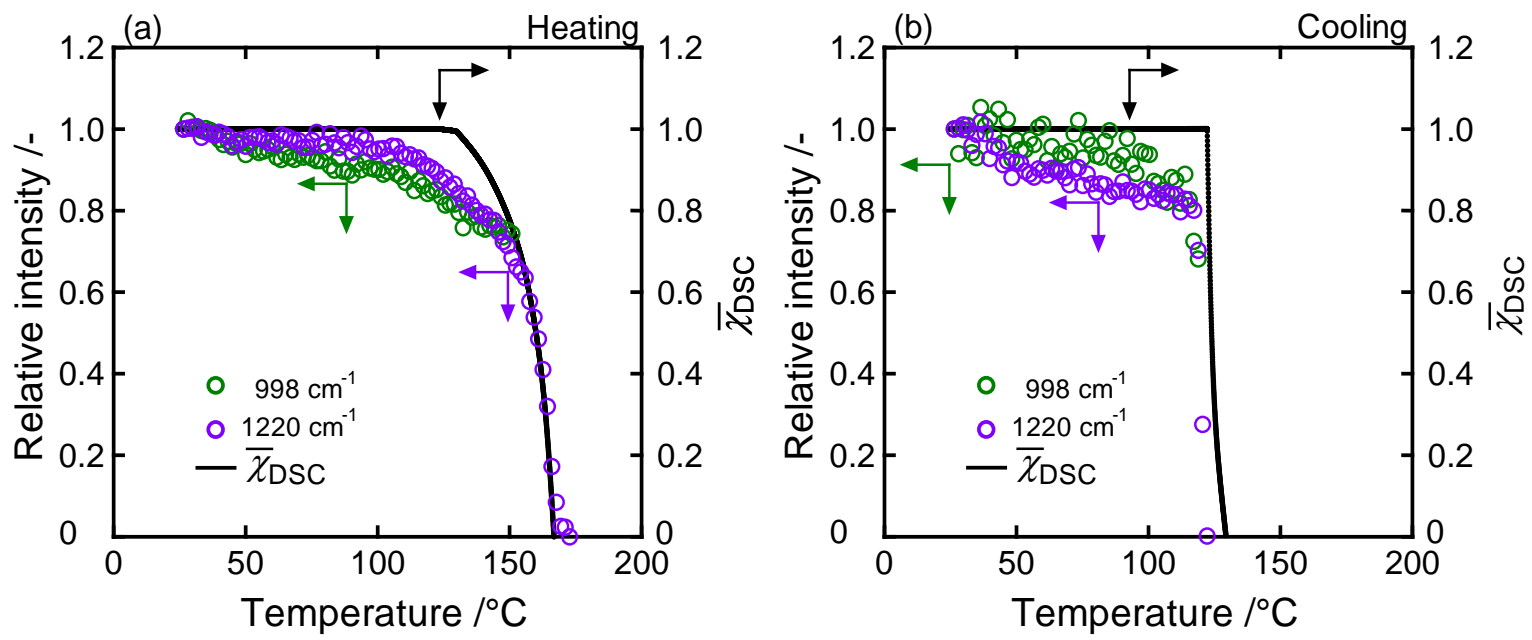

Figure 6. Temperature dependence of the relative intensities of the regularity bands and relative crystallinity estimated from the DSC curves under (a) heating and (b) cooling processes at heating/cooling rates of $\pm 2{ }^{\circ} \mathrm{C} / \mathrm{min}$. 
In situ Raman spectra of iPP during heating are shown in Fig. 7. Both the 400 and 1330 $\mathrm{cm}^{-1}$ bands show clear peaks over the entire temperature range from the solid state to the melt state, although the peaks somewhat broaden in the melt state. These bands are composed of two bands: a sharp crystalline band and a weak and broad amorphous band. In fact, the intensity of the crystalline band slightly decreases with increasing temperature even below the melting temperature. However, because of the sufficiently high crystallinity of iPP (62\% at room temperature), the amorphous peaks are too weak to separate. In addition, the overall spectral shapes are maintained with heating to the melting temperature. We then focused on the peak position of the crystalline band, which can be interpreted by the thermal expansion of the unit cell. ${ }^{14}$ The $400 \mathrm{~cm}^{-1}$ band gradually shifts to a higher wave number and it shows an appreciable blue shift at the melting temperature of $167{ }^{\circ} \mathrm{C}$ accompanied by substantial broadening. The $1330 \mathrm{~cm}^{-1}$ band shows a gradual red shift in the solid phase, and it broadens and slightly shifts to a lower wave number at the melting transition. These spectral shifts in opposite directions can be understood by considering the changes in the crystalline structures. 
(a)

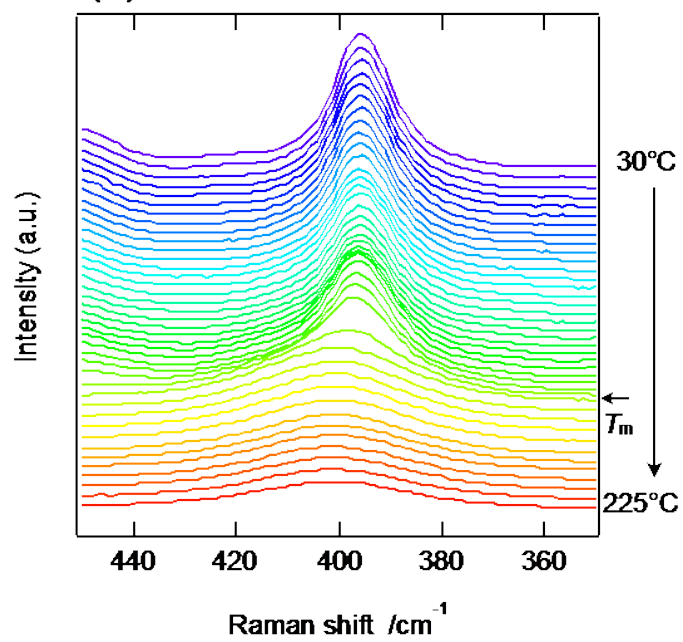

(b)

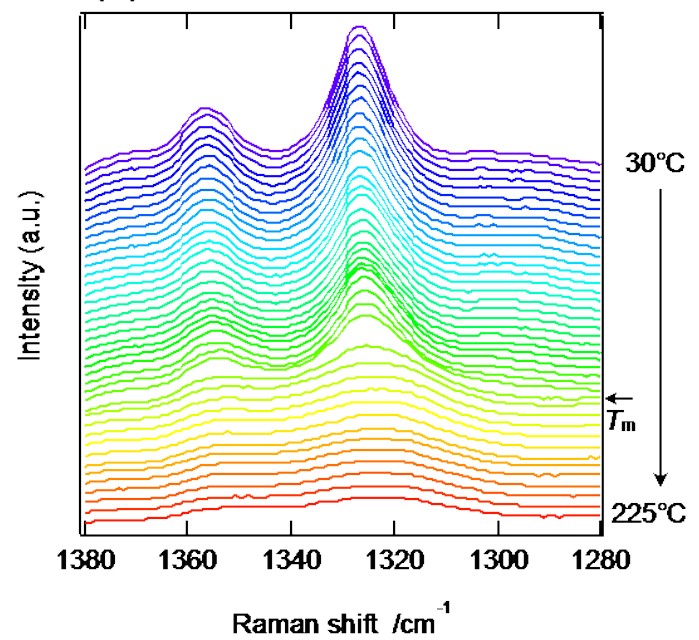

Figure 7. In situ Raman spectra of iPP in the (a) 400 and (b) $1330 \mathrm{~cm}^{-1}$ regions at temperatures from 30 to $225{ }^{\circ} \mathrm{C}$ (from top to bottom) at $5{ }^{\circ} \mathrm{C}$ intervals during heating at a rate of $2{ }^{\circ} \mathrm{C} / \mathrm{min}$. The melting temperature $T_{\mathrm{m}}$ is indicated by the arrows.

WAXD profiles of iPP at various temperatures are shown in Fig. 8. The Bragg peaks at 14, 17, 19, 21, and $22^{\circ}$ are assigned to diffraction from the (110), (040), (130), (111), and (041) planes, respectively. ${ }^{48,49}$ These Bragg peaks slightly shift to lower angles with increasing temperature, indicating increases of the lattice distances. The temperature dependences of the lattice constants are shown in Fig. 9. The lattice constant $b$ significantly increases with increasing temperature, and $a^{*}$ also shows a slight increase. This suggests expansion of the $a^{*} b$ plane, which is perpendicular to the chain axis ( $c$ axis). The significant decrease in lattice constant $c$ with increasing temperature suggests contraction along the chain axis. Similar anisotropic thermal expansion has been found in previous studies. ${ }^{50,51}$ 


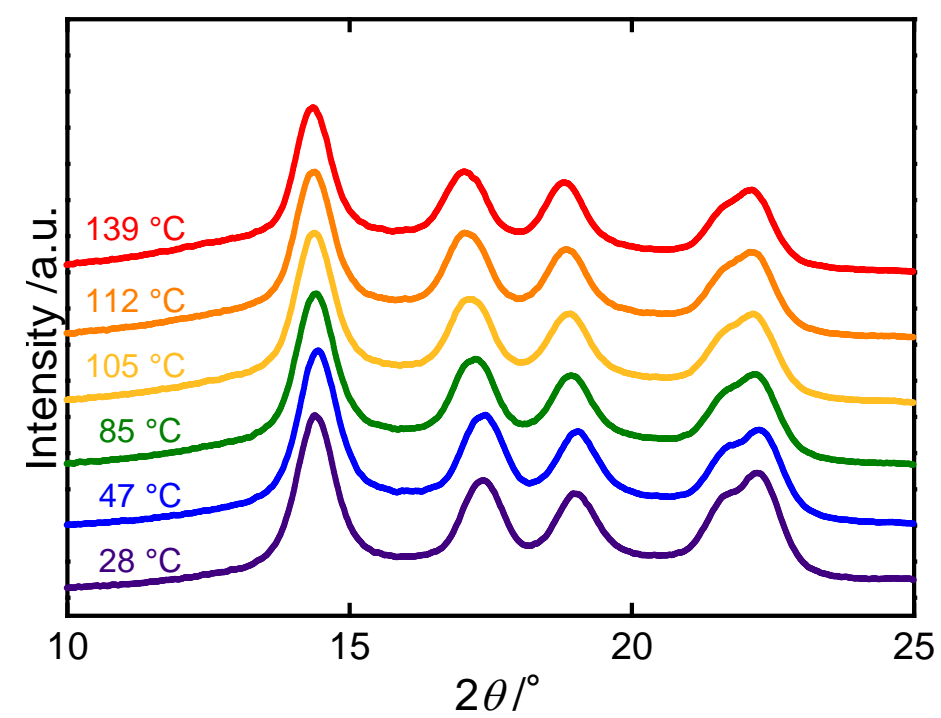

Figure 8. WAXD profiles of iPP at various temperatures.
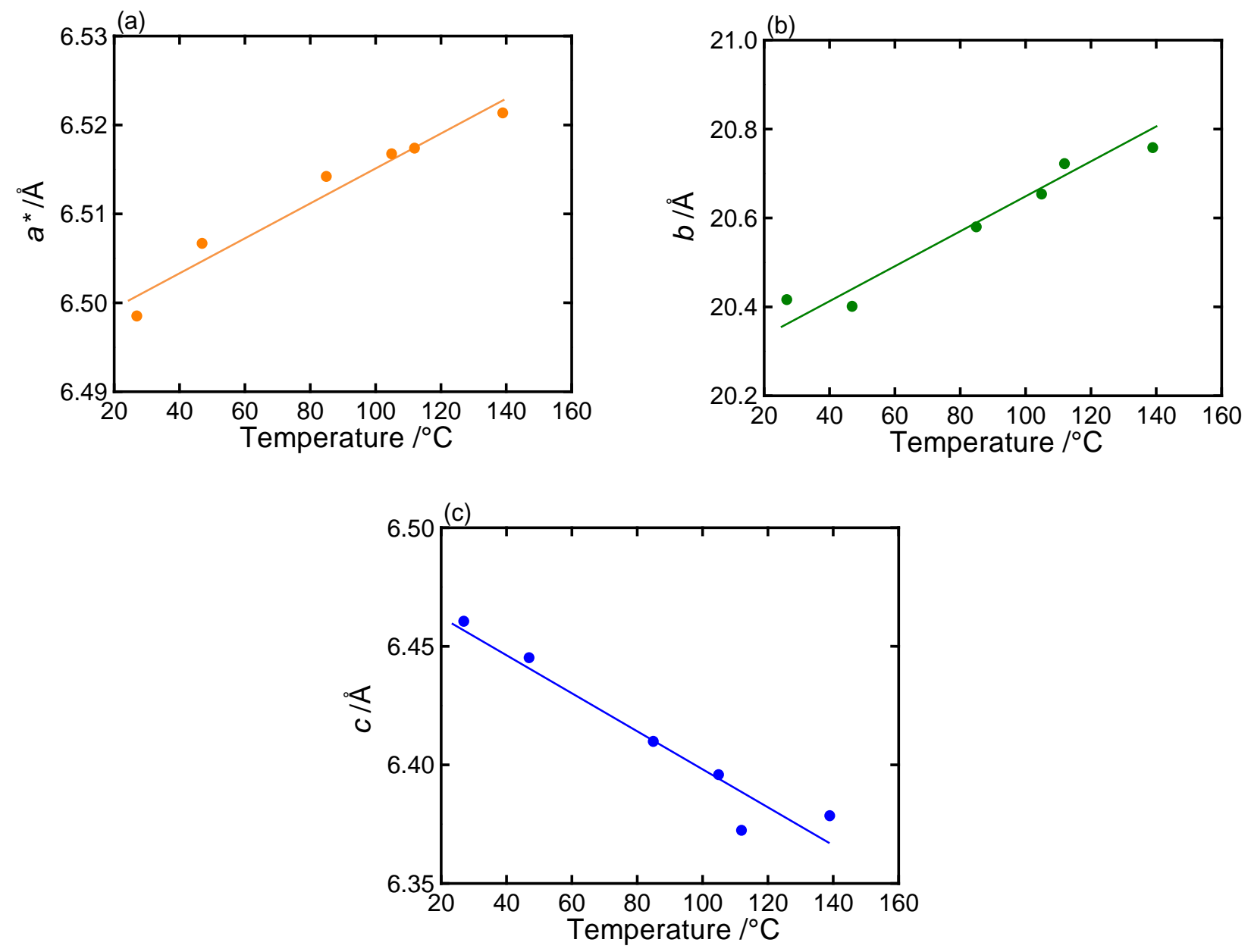

Figure 9. Temperature dependences the (a) $a^{*}$, (b) $b$, and (c) $c$ lattice parameters of iPP. 
The expansion of the area of the $a^{*} b$ plane results in an increase of the interchain distance. It is then likely that the twisting motions of the $\mathrm{CH}_{2}$ groups are promoted at high temperature, resulting in a red shift of the $1330 \mathrm{~cm}^{-1}$ band. Because there are four helical chains in the unit cell perpendicular to the $a^{*} b$ plane, the interchain distance can be characterized by $l_{\perp}=\left(a^{*} b / 4\right)^{1 / 2}$. This characteristic length $l_{\perp}$ is compared with the peak shift of the $1330 \mathrm{~cm}^{-1}$ band $\Delta v_{1330}$ in Fig. 10(a). Because these two values show a good linear correlation in the entire solid phase, the red shift of the $1330 \mathrm{~cm}^{-1}$ band is interpreted as an increase in the interchain distance owing to expansion of the $a^{*} b$ plane. As a result, the value of $l_{\perp}$ (in $\AA$ ) can be expressed as a linear function of $\Delta v_{1330}$ :

$$
l_{\perp} \equiv \sqrt{\frac{a^{*} b}{4}} \approx-8.35 \times 10^{-2} \Lambda v_{1330}+5.73
$$
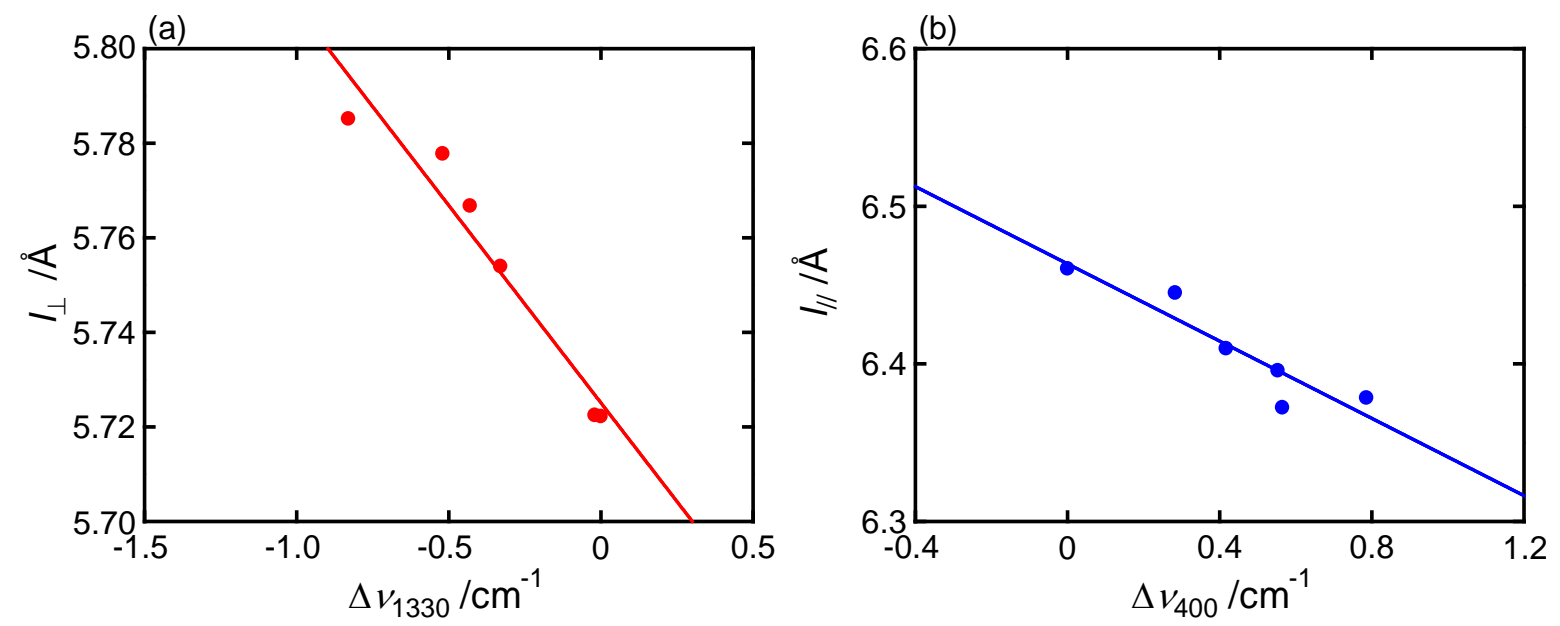

Figure 10. Relation between the peak shifts of the 1330 and $400 \mathrm{~cm}^{-1}$ bands and the characteristic lengths perpendicular $\left(l_{\perp}\right)$ and parallel $\left(l_{/ /}\right)$to the chain axis in the solid phase.

Considering that the $400 \mathrm{~cm}^{-1}$ band shows a slight red shift under stretching along the chain axis, $^{52}$ the blue shift of the $400 \mathrm{~cm}^{-1}$ band reflects contraction along the $c$ axis. The lattice 
constant $c$ corresponding to the period along the chain axis $\left(l_{/ /}=c\right)$ shows a linear correlation with $\Delta v_{400}$, as shown in Fig. 10(b). It then follows that the value of $l_{/ /}$(in $\AA$ ) can be expressed as a linear function of $\Delta v_{400}$ :

$$
l_{l l} \equiv c \approx-0.123 \Lambda v_{400}+6.46
$$

Although the linear relationships of Eqs. (7) and (8) result from the spectral assignments of the 400 and $1330 \mathrm{~cm}^{-1}$ bands, experimental evidence of these linear relationships is limited. The validity of these linear relationships can be verified by further investigation in a wide range of the solid phase including extreme conditions, such as low temperatures and high pressures.

The $400 \mathrm{~cm}^{-1}$ band is sensitive to conformational disorder. ${ }^{27,28}$ It has been reported that the $400 \mathrm{~cm}^{-1}$ band is essentially reproduced by skeletal vibration, where the hydrogen motions are omitted in the calculation. ${ }^{28}$ The blue shift of the $400 \mathrm{~cm}^{-1}$ band with increasing temperature can then be explained by the increase in the conformational disorder of the crystalline chains leading to an increase of the natural frequency of the coupled oscillators of the helical chain, which is similar to the disordered longitudinal acoustic mode (D-LAM). ${ }^{53}$ This interpretation is consistent with normal coordinate analysis ${ }^{27}$ of iPP, which predicts that helical chains shorter than $n=6$ give a shoulder peak on the blue side of the $400 \mathrm{~cm}^{-1}$ band. There are good correlations between $\Delta v_{400}$ and the relative intensities of the regularity bands at 998 and $1220 \mathrm{~cm}^{-1}$ in the whole solid phase, as shown in Fig. 11. It is likely that distortion of the crystalline stems is closely related to the decrease of the helical sequences. Combining with the WAXD results in Fig. 10(b), we suggest that conformational disorder also results in contraction along the $c$ axis. 


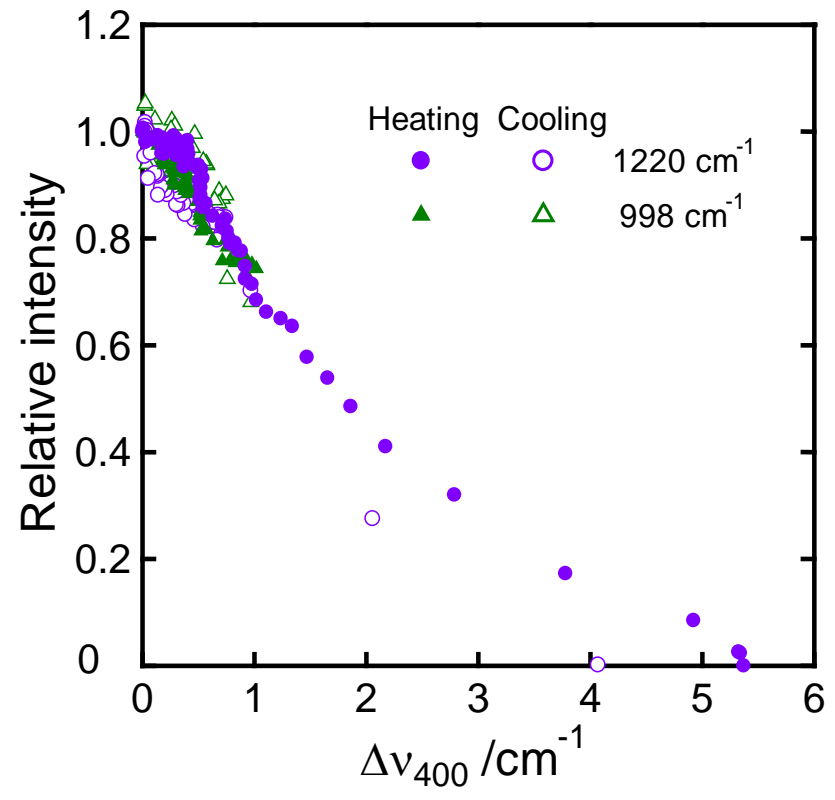

Figure 11. Relative intensities of the 998 and $1220 \mathrm{~cm}^{-1}$ bands versus the peak shift of the 400 $\mathrm{cm}^{-1}$ band under heating and cooling processes.

The temperature dependences of $\Delta v_{400}, \Delta v_{1330}$, and $\bar{\chi}_{\mathrm{Dsc}}(T)$ are shown in Fig. 12. In the solid phase during heating, while $\bar{\chi}_{\mathrm{Dsc}}(T)$ remains one, the 400 and $1330 \mathrm{~cm}^{-1}$ bands show gradual blue and red shifts, respectively. This suggests that conformational disorder and the interchain distance increase at the molecular level, even though no significant change is detected by thermal analysis. Above about $120^{\circ} \mathrm{C}$, the slope of $\Delta v_{400}$ shows a slight increase, which is consistent with the decrease of the helical sequences in Fig. 6. At the melting point of $167{ }^{\circ} \mathrm{C}$, these shifts show abrupt increases, suggesting that the chain conformation becomes highly disordered and the interchain distance significantly increases owing to the melting transition. In the melt state, where the crystalline structure has disappeared, the blue shift of the $400 \mathrm{~cm}^{-1}$ band occurs more gradually, suggesting that the chain conformation is highly disordered and it gradually approaches a random conformation at a sufficiently high temperature. Even in the melt 
state, the red shift of the $1330 \mathrm{~cm}^{-1}$ band still linearly increases with increasing temperature, indicating that the $\mathrm{CH}_{2}$ twisting motions are further promoted with increasing temperature in the melt state. In the melt state, the temperature dependence of $\Delta v_{1330}$ is stronger than that of $\Delta v_{400}$, which can be explained by the anisotropy of the interactions between the parallel and perpendicular directions with respect to the chain axis. The van der Waals interactions in the interchain direction are likely to weaken with the increase of the interchain distance owing to thermal expansion, whereas the covalent bonds of the polymer chain are less affected after a sufficiently random conformation is attained upon melting.

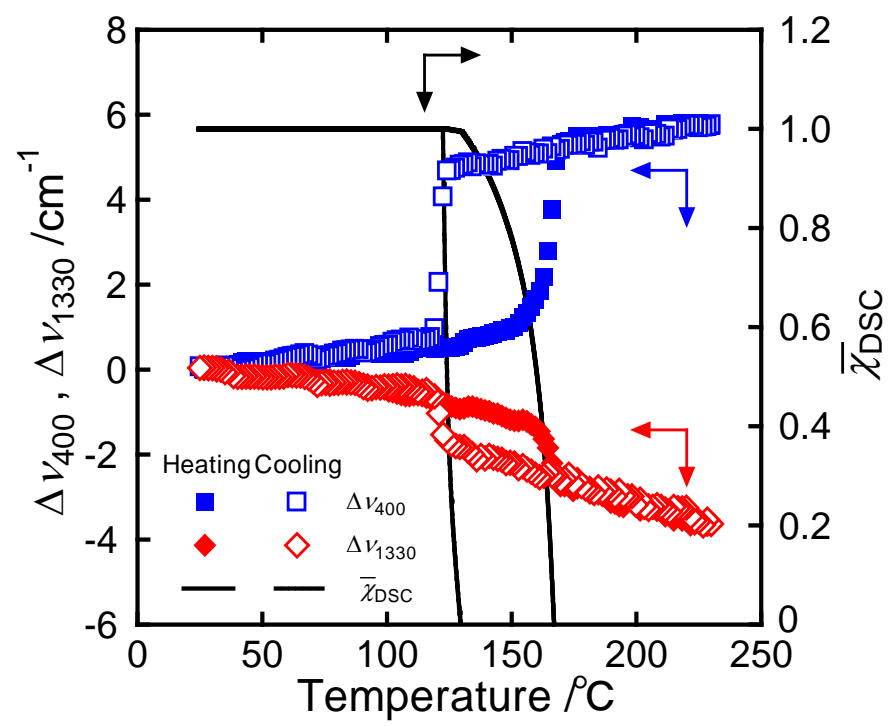

Figure 12. Temperature dependences of the peak shifts of the 400 (blue) and $1330 \mathrm{~cm}^{-1}$ (red) bands and the relative crystallinity from DSC measurements (black) under heating (solid symbols and solid line) and cooling (open symbols and dashed line) processes at heating/cooling rates of $\pm 2{ }^{\circ} \mathrm{C} / \mathrm{min}$. 
During the cooling process, the values of the peak shifts are identical to those during the heating process, except for the supercooled region between 167 and $122{ }^{\circ} \mathrm{C}$ where the peak shifts show obvious hystereses (see Fig. 12). The hysteresis loops of these Raman shifts are consistent with the results of a molecular dynamics simulation of helical polymers, which predicted the hysteresis of the average helix length, as well as the global order parameter ${ }^{54}$ In the melt state, the slope of the $1330 \mathrm{~cm}^{-1}$ band is significantly steeper than that of the $400 \mathrm{~cm}^{-1}$ band, suggesting that the interchain approach is predominant, while the chain conformation is still significantly disordered before crystallization. In the supercooled region, the molecular structural changes continue to proceed at the same rates as those at relatively high temperatures, and abrupt changes in the inter- and intrachain structures simultaneously occur at the crystallization temperature. Even after the drastic change at the crystallization temperature, microscopic structural changes still occur owing to the decrease of the interchain distance and conformational ordering of the helical chains.

As shown in Fig. 13, at faster heating/cooling rates of $\pm 15{ }^{\circ} \mathrm{C} / \mathrm{min}$, the crystallinity significantly changes, the melting transition begins at a lower temperature, and the crystallization temperature is $\sim 10{ }^{\circ} \mathrm{C}$ lower. Despite these differences in the thermal analysis, the trends of $\Delta v_{400}$ and $\Delta v_{1330}$ are essentially unaffected by the heating and cooling rates. The values of $\Delta v_{400}$ and $\Delta v_{1330}$ are also insensitive to the molecular weight, as shown in Fig. 14 where the values for iPP with a lower molecular weight of $M_{\mathrm{w}}=22 \times 10^{4}$ are plotted. This suggests that the heating/cooling rate and molecular weight have little effect on the molecular mechanism of melting and crystallization, although these parameters have a strong influence on the crystallization phenomena at larger scales, such as crystal growth and formation of spherulites. 


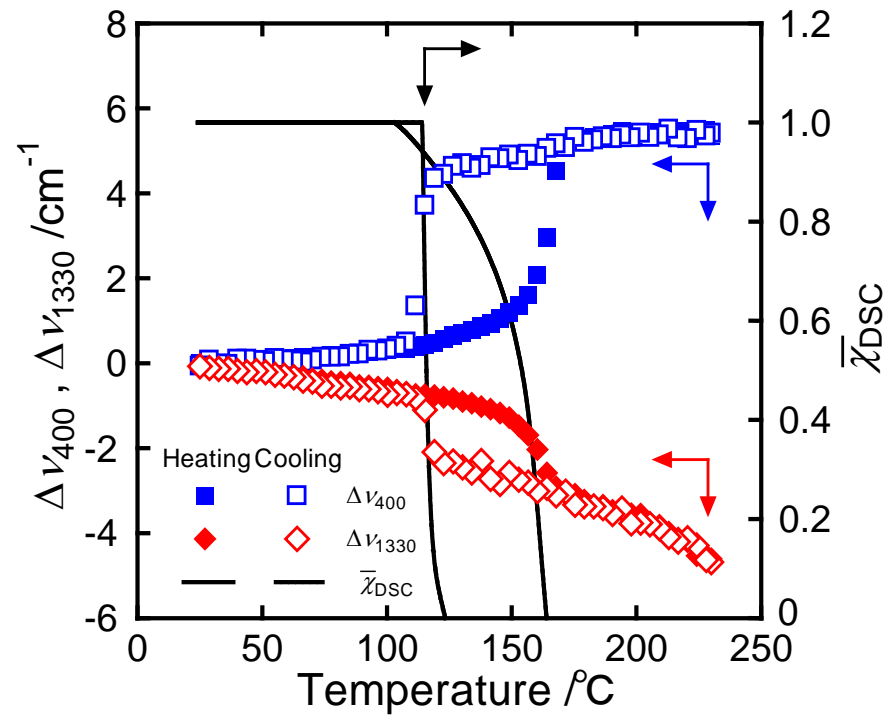

Figure 13. Temperature dependences of the peak shifts of the 400 (blue) and $1330 \mathrm{~cm}^{-1}$ (red) bands and the relative crystallinity from DSC measurements (black) under heating (solid symbols and solid line) and cooling (open symbols and dashed line) processes at heating/cooling rates of $\pm 15^{\circ} \mathrm{C} / \mathrm{min}$. 


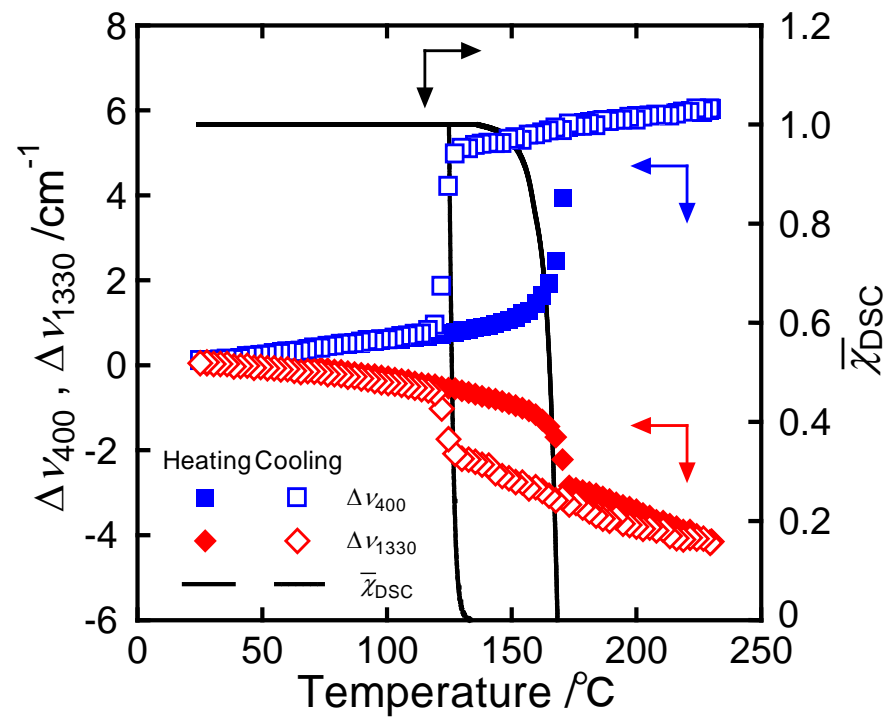

Figure 14. Temperature dependences of the peak shifts of the 400 (blue) and $1330 \mathrm{~cm}^{-1}$ (red) bands and the relative crystallinity from DSC measurement (black) under heating (solid symbols and solid line) and cooling (open symbols and dashed line) processes at heating/cooling rates of $\pm 2{ }^{\circ} \mathrm{C} / \mathrm{min}$ for iPP with $M_{\mathrm{w}}=22 \times 10^{4}$.

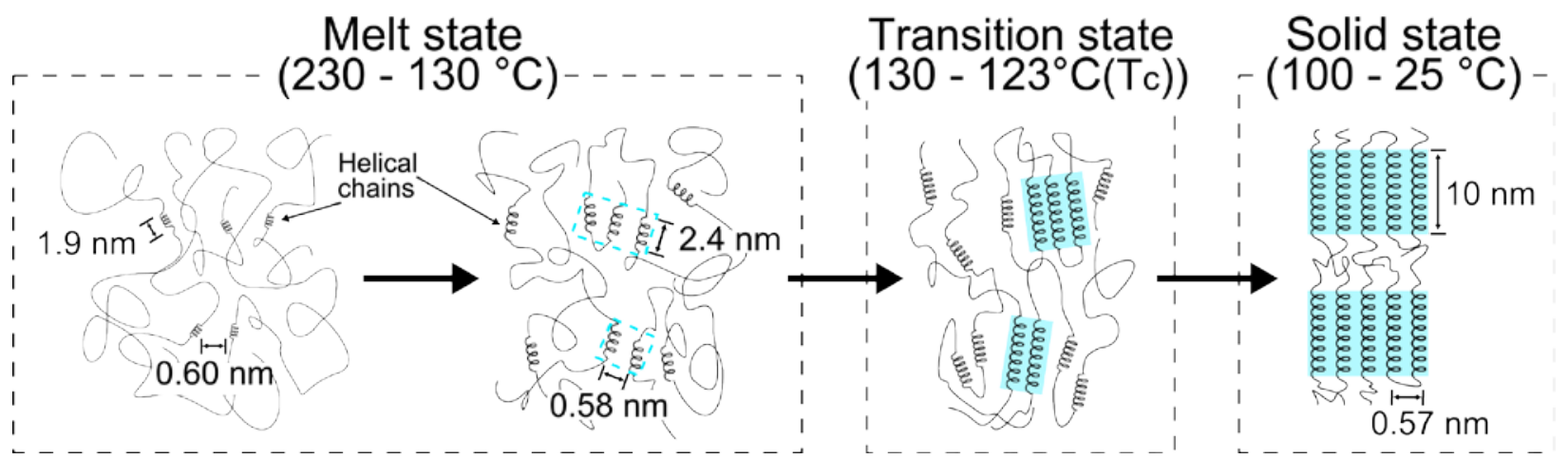

Figure 15. Schematic diagram of the molecular mechanism of iPP crystallization.

The molecular mechanism of iPP crystallization is shown in Fig. 15. Although the linear relations of Eqs. (7) and (8) are obtained in the solid state, extrapolation of these relations to the 
melt state enables the characteristic sizes along and perpendicular to the chain axis to be determined. Because short helical chains $(n \leq 10)$ exist in the melt, ${ }^{37,38}$ the interchain distance and the maximum length of the $3{ }_{1}$ helical sequences at $230{ }^{\circ} \mathrm{C}$ are estimated to be $l_{\perp} \approx 0.60 \mathrm{~nm}$ and $(n / 3) \times l_{/ /} \approx 1.9 \mathrm{~nm}$, respectively. The interchain distance of $0.60 \mathrm{~nm}$ at $230{ }^{\circ} \mathrm{C}$ is considerably larger than that at room temperature (by $\sim 5 \%$ ). Even though the temperature effect on $\Delta v_{1330}$ is not taken into account, this value is consistent with the decrease of the density estimated by the difference in the densities between the amorphous phase $\left(\rho_{\mathrm{a}}=854 \mathrm{~kg} / \mathrm{m}^{3}\right)^{55}$ and iPP sheets at room temperature $\left(\rho=905 \mathrm{~kg} / \mathrm{m}^{3}\right)$ determined by the Archimedes method. In the melt state, the interchain distance considerably decreases to $\sim 0.58 \mathrm{~nm}$ with decreasing temperature before crystallization $\left(130{ }^{\circ} \mathrm{C}\right)$. The critical stem size is estimated to be $(n / 3) \times l_{/ /} \approx 2.4 \mathrm{~nm}$ by considering the length of the helical sequences at crystallization $(n=12) .{ }^{15,37}$ It has been reported that the radius of gyration slightly decreases from 35 to $20 \mathrm{~nm}$ during isothermal crystallization of iPP and short helices form. ${ }^{10}$ It is then plausible that the stems correspond to the short helix in the domain. The critical stem size of $2.4 \mathrm{~nm}$ is in good agreement with the value of $2.38 \mathrm{~nm}$ determined by IR analysis and theoretical consideration. ${ }^{37}$ The increase of the stem length when approaching the crystallization temperature may lead to formation of the mesomorphic phase. $^{56}$ The sequence length of the helix conformation in the supercooled state is determined by the freeenergy balance between the energy loss, which is proportional to the length of the crystalline sequence, and the loss of conformational entropy under thermal fluctuation. The stiffened stems can align parallel to reduce the excluded volume interaction of rod-like segments, ${ }^{57}$ and the orientation of chains may also promote crystallization. ${ }^{58}$ At the crystallization temperature, a stem consisting of a long helical chain forms accompanied by a slight decrease of the interchain distance ( 1\%). Fluctuation in the crystalline structure occurs down to $\sim 100{ }^{\circ} \mathrm{C}$, where the 
interchain distance decreases by $\sim 1 \%$ and the crystalline axis elongates by $\sim 2 \%$. At room temperature, the lamellar crystalline thickness is $10 \mathrm{~nm}$ (determined by a small-angle $\mathrm{X}$-ray scattering measurement) and the average interchain distance is $0.57 \mathrm{~nm}$.

\section{CONCLUSIONS}

In situ Raman spectroscopy has been used to investigate the molecular mechanisms of iPP during melting and crystallization. The crystallinity was determined with the intensities of the 808, 830 , and $840 \mathrm{~cm}^{-1}$ bands. The crystallinity gradually decreases with increasing temperature above $\sim 100{ }^{\circ} \mathrm{C}$ followed by a sharp decrease at the melting temperature in accordance with the decrease of the $n=10$ and 14 helical chains determined from the relative intensities of the 998 and $1220 \mathrm{~cm}^{-1}$ bands, respectively. During the heating process, the $400 \mathrm{~cm}^{-1}$ band $\left(\Delta v_{400}\right)$ assigned to the $\mathrm{C}-\mathrm{C}-\mathrm{C}$ bending mode shifts to higher wave number, suggesting an increase in the conformational disorder of the crystalline stem. The $1330 \mathrm{~cm}^{-1}$ band $\left(\Delta v_{1330}\right)$ assigned to the $\mathrm{CH}_{2}$ twisting mode shifts to lower wave number, suggesting enhancement of the $\mathrm{CH}_{2}$ vibration owing to an increase of the interchain distance. At the melting temperature, $\Delta v_{400}$ shows a marked blue shift and the temperature dependence becomes weaker in the melt, suggesting that the chain conformation becomes disordered during melting. Conversely, $\Delta v_{1330}$ shows a significant red shift at the melting point and the slope becomes steeper in the melt, suggesting enhancement of $\mathrm{CH}_{2}$ vibration even in the melt, presumably because of an increase in the interchain distance. During the cooling process, the values of $\Delta v_{400}$ and $\Delta v_{1330}$ lie on the same curves as those during heating, except for the supercooled region where each peak shift shows 
clear hysteresis. The microscopic structural changes along and perpendicular to the molecular chains were evaluated by combining the Raman spectroscopy results with the results of WAXD analysis. Extrapolation of the linear relationship to the melt state suggests that the interchain distance significantly decreases with cooling before crystallization (by $\sim 3 \%$ ), and the critical stem size for crystallization is estimated to be $\sim 2.4 \mathrm{~nm}$. The results also suggest that the interchain distance decreases by $\sim 1 \%$ and the crystalline axis elongates by $2 \%$ during cooling in the solid state.

\section{AUTHOR INFORMATION}

\section{Corresponding Author}

*Koh-hei Nitta (nitta@se.kanazawa-u.ac.jp), Department of Chemical and Materials Science, Kanazawa University, Kakuma Campus, Kanazawa 920-1192, Japan

\section{Funding Sources}

This work was financially supported by JSPS KAKENHI (Grant Number 26410221).

\section{REFERENCES}

(1) Eder, M.; Wlochowicz, A. Kinetics of Non-Isothermal Crystallization of Polyethylene and Polypropylene. Polymer (Guildf). 1983, 24 (12), 1593-1595.

(2) Clark, E. J.; Hoffman, J. D. Regime III Crystallization in Polypropylene. Macromolecules 1984, 17 (4), 878-885.

(3) Monasse, B.; Haudin, J. M. Growth Transition and Morphology Change in Polypropylene. Colloid Polym. Sci. 1985, 263 (10), 822-831.

(4) Norton, D. R.; Keller, A. The Spherulitic and Lamellar Morphology of Melt-Crystallized Isotactic Polypropylene. Polymer (Guildf). 1985, 26 (5), 704-716. 
(5) Gaceva, G. B.; Janevski, A.; Grozdanov, A. Crystallization and Melting Behavior of iPP Studied by DSC. J. Appl. Polym. Sci. 1998, 67 (3), 395-404.

(6) Long, Y.; Shanks, R. A.; Stachurski, Z. H. Kinetics of Polymer Crystallisation. Prog. Polym. Sci. 1995, 20 (4), 651-701.

(7) Pasquini, N. Polypropylene Handbook; Carl Hanser Verlag: Munich, 2005.

(8) Strobl, G. Colloquium: Laws Controlling Crystallization and Melting in Bulk Polymers. Rev. Mod. Phys. 2009, 81 (3), 1287-1300.

(9) Dai, P. S.; Cebe, P.; Capel, M.; Alamo, R. G.; Mandelkern, L. In Situ Wide- and SmallAngle X-Ray Scattering Study of Melting Kinetics of Isotactic Poly(propylene).

Macromolecules 2003, 36 (11), 4042-4050.

(10) Reddy, K. R.; Tashiro, K.; Sakurai, T.; Yamaguchi, N.; Sasaki, S.; Masunaga, H.; Takata, M. Isothermal Crystallization Behavior of Isotactic Polypropylene H/D Blends as Viewed from Time-Resolved FTIR and Synchrotron SAXS/WAXD Measurements.

Macromolecules 2009, 42 (12), 4191-4199.

(11) Wang, Z.-G.; Hsiao, B. S.; Sirota, E. B.; Agarwal, P.; Srinivas, S. Probing the Early Stages of Melt Crystallization in Polypropylene by Simultaneous Small- and Wide-Angle X-Ray Scattering and Laser Light Scattering. Macromolecules 2000, 33 (3), 978-989.

(12) Iijima, M.; Strobl, G. Isothermal Crystallization and Melting of Isotactic Polypropylene Analyzed by Time- and Temperature-Dependent Small-Angle X-Ray Scattering Experiments. Macromolecules 2000, 33 (14), 5204-5214.

(13) Cong, Y.; Hong, Z.; Zhou, W.; Chen, W.; Su, F.; Li, H.; Li, X.; Yang, K.; Yu, X.; Qi, Z.; $\mathrm{Li}$, L. Conformational Ordering on the Growth Front of Isotactic Polypropylene Spherulite. Macromolecules 2012, 45 (21), 8674-8680.

(14) Brookes, A.; Dyke, J. M.; Hendra, P. J.; Meehan, S. The FT-Raman Spectroscopic Study of Polymers at Temperatures in Excess of $200^{\circ} \mathrm{C}$. Spectrochim. Acta Part A Mol. Biomol. Spectrosc. 1997, 53 (13), 2313-2321.

(15) Khafagy, R. M. In Situ FT-Raman Spectroscopic Study of the Conformational Changes Occurring in Isotactic Polypropylene during Its Melting and Crystallization Processes. $J$. Polym. Sci. Part B Polym. Phys. 2006, 44 (15), 2173-2182.

(16) Migler, K. B.; Kotula, A. P.; Hight Walker, A. R. Trans -Rich Structures in Early Stage Crystallization of Polyethylene. Macromolecules 2015, 48 (13), 4555-4561.

(17) Nielsen, A. S.; Batchelder, D. N.; Pyrz, R. Estimation of Crystallinity of Isotactic Polypropylene Using Raman Spectroscopy. Polymer (Guildf). 2002, 43 (9), 2671-2676. 
(18) Gatos, K. G.; Minogianni, C.; Galiotis, C. Quantifying Crystalline Fraction within Polymer Spherulites. Macromolecules 2007, 40 (4), 786-789.

(19) Minogianni, C.; Gatos, K. G.; Galiotis, C. Estimation of Crystallinity in Isotropic Isotactic Polypropylene with Raman Spectroscopy. Appl. Spectrosc. 2005, 59 (9), 1141-1147.

(20) Kissin, Y. V.; Rishina, L. A. Regularity Bands in the I.R. Spectra of $\mathrm{C}_{3} \mathrm{H}_{6}-\mathrm{C}_{3} \mathrm{D}_{6}$ Copolymers. Eur. Polym. J. 1976, 12 (10), 757-759.

(21) Kissin, Y. V.; Tsvetkova, V. I.; Chirkov, N. M. The Stereoregularity of Polypropylene from I.R. and NMR Data. Eur. Polym. J. 1972, 8 (4), 529-546.

(22) Miyamoto, T.; Inagaki, H. Structural and Steric Isomerism of Polypropylenes. J. Polym. Sci. Part B Polym. Phys. 1969, 7 (6), 963-981.

(23) Hsu, S. L.; Krimm, S.; Krause, S.; Yeh, G. S. Y. Longitudinal Acoustic Mode in Isotactic Polypropylene. J. Polym. Sci. Part C Polym. Lett. 1976, 14 (4), 195-200.

(24) Rabolt, J. F.; Fanconi, B. Longitudinal Acustic Mode in Helical Polymers: Poly(oxymethylene) and Isotactic Polypropylene. J. Polym. Sci. Part C Polym. Lett. 1997, 15 (3), 121-127.

(25) Hsu, S. L.; Krimm, S. Longitudinal Acoustic Mode in Polymers. J. Appl. Phys. 1976, 47 (10), 4265-4270.

(26) Glotin, M.; Rahalkar, R. R.; Hendra, P. J.; Cudby, M. E. A.; Willis, H. A. Some Crystallization Kinetics of Isotactic Polypropylene. Polymer (Guildf). 1981, 22, 731-735.

(27) Hahn, T.; Suen, W.; Kang, S.; Hsu, S. L.; Stidham, H. D.; Siedle, A. R. An Analysis of the Raman Spectrum of Syndiotactic Polypropylene. 1. Conformational Defects. Polymer (Guildf). 2001, 42 (13), 5813-5822.

(28) Hallmark, V. M.; Bohan, S. P.; Strauss, H. L.: Snyder, R. G. Analysis of the LowFrequency Isotropic Raman Spectrum of Molten Isotactic Polypropylene. Macromolecules 1991, 24 (14), 4025-4032.

(29) Brückner, S.; Meille, S. V; Petraccone, V.: Pirozzi, B. Polymorphism in Isotactic Polypropylene. Prog. Polym. Sci. 1991, 16 (2-3), 361-404.

(30) Lotz, B. $\alpha$ and $\beta$ Phases of Isotactic Polypropylene: A Case of Growth Kinetics 'Phase Reentrency' in Polymer Crystallization. Polymer (Guildf). 1998, 39 (19), 4561-4567.

(31) Nakamura, K.; Shimizu, S.; Umemoto, S.; Thierry, A.; Lotz, B.; Okui, N. Temperature Dependence of Crystal Growth Rate for $\alpha$ and $\beta$ Forms of Isotactic Polypropylene. Polym. J. 2008, 40 (9), 915-922. 
(32) Jiang, Q.-H.; Zhang, C.-B.; Yang, J.; Zhao, Y.; Xu, Y.-Z.; Wang, D.-J. Investigation on Structural Changes of Isotactic Polypropylene Mesophase in the Heating Process by Using Two-Dimensional Infrared Correlation Spectroscopy. Chinese Chem. Lett. 2015, 26 (2), 197-199.

(33) Zhao, J.; Wang, Z.; Niu, Y.; Hsiao, B. S.; Piccarolo, S. Phase Transitions in Prequenched Mesomorphic Isotactic Polypropylene during Heating and Annealing Processes as Revealed by Simultaneous Synchrotron SAXS and WAXD Technique. J. Phys. Chem. B 2012, 116 (1), 147-153.

(34) Meille, S. V.; Bruckner, S.; Porzio, W. $\gamma$-Isotactic Polypropylene. A Structure with Nonparallel Chain Axes. Macromolecules 1990, 23 (18), 4114-4121.

(35) Natta, G.; Corradini, P. Structure and Properties of Isotactic Polypropylene. Nuovo Cim. 1960, 15 (1), 40-51.

(36) Hikosaka, M.; Seto, T. The Order of the Molecular Chians in Isotactic Polypropylene Crystals. Polym. J. 1973, 5 (2), 111-127.

(37) Zhu, X.; Yan, D.; Fang, Y. In Situ FTIR Spectroscopic Study of the Conformational Change of Isotactic Polypropylene during the Crystallization Process. J. Phys. Chem. B 2001, 105 (50), 12461-12463.

(38) Zhu, X.; Yan, D.; Yao, H.; Zhu, P. In Situ FTIR Spectroscopic Study of the Regularity Bands and Partial-Order Melts of Isotactic Poly(propylene). Macromol. Rapid Commun. 2000, 21 (7), 354-357.

(39) Zhu, X.; Yan, D. In Situ FTIR Spectroscopy Study on the Melting Process of Isotactic Poly(propylene). Macromol. Chem. Phys. 2001, 202 (7), 1109-1113.

(40) Zhu, X.; Fang, Y.; Yan, D. A Possible Explanation to the Structure Change of Isotactic Polypropylene Occurring at about $135^{\circ} \mathrm{C}$. Polymer (Guildf). 2001, 42 (21), 8595-8598.

(41) Kida, T.; Hiejima, Y.; Nitta, K. H-. Raman Spectroscopic Study of High-Density Polyethylene during Tensile Deformation. Int. J. Exp. Spectrosc. Tech. 2016, 1 (1), 1-6.

(42) Hendra, P. J.; Vile, J.; Willis, H. A.; Zichy, V.; Cudby, M. E. A. The Effect of Cooling Rate upon the Morphology of Quenched Melts of Isotactic Polypropylenes. Polymer (Guildf). 1984, 25 (6), 785-790.

(43) Sundell, T.; Fagerholm, H.; Crozier, H. Isotacticity Determination of Polypropylene Using FT-Raman Spectroscopy. Polymer (Guildf). 1996, 37 (15), 3227-3231.

(44) Snyder, R. G.; Schachtschneider, J. H. Valence Force Calculation of the Vibrational Spectra of Crystalline Isotactic Polypropylene and Some Deuterated Polypropylenes. Spectrochim. Acta 1964, 20 (5), 853-869. 
(45) Grasf, M. D.; McHenry, M. E. Structure of Materials; Cambridge University Press: New York, 2012.

(46) Bower, D. I.; Maddams, W. F. The Vibrational Spectroscopy of Polymers, Cambridge University Press: New York, 1992.

(47) Chen, Z.; Hay, J. N.; Jenkins, M. J. The thermal analysis of poly (ethylene terephthalate) by FTIR spectroscopy. Thermochim. Acta 2013, 552, 123-130.

(48) Androsch, R.; Wunderlich, B. Reversible Crystallization and Melting at the Lateral Surface of Isotactic Polypropylene Crystals. Macromolecules 2001, 34 (17), 5950-5960.

(49) Miller, R. L. On the Existence of Near-Range Order in Isotactic Polypropylenes. Polymer (Guildf). 1960, 1, 135-143.

(50) Naiki, M.; Kikkawa, T.; Endo, Y.; Nozaki, K.; Yamamoto, T.; Hara, T. Crystal Ordering of a Phase Isotactic Polypropylene. Polymer (Guildf). 2001, 42 (12), 5471-5477.

(51) Isasi, J. R.; Alamo, R. G.; Mandelkern, L. The Thermal Expansion of the Monoclinic Unit Cell of Isotactic Polypropylene. J. Polym. Sci. Part B Polym. Phys. 1997, 35 (17), 29452949.

(52) Tashiro, K.; Minami, S.; Wu, G.; Kobayashi, M. Quasiharmonic Treatment of Infrared and Raman Vibrational Frequency Shifts Induced by Tensile Deformation of Polymer Chains . II . Application to the Polyoxymethylene and Lsotactic Polypropylene Single Chains and the Three-Dimensional Orthorhombic Polyethylene crystal. J. Polym. Sci. Part B Polym. Phys. 1992, 30 (10), 1143-1155.

(53) Snyder, R. G. The Structure of Chain Molecules in the Liquid State: Low-Frequency Raman Spectra of n-Alkanes and Perfluoro-n-alkanes. J. Chem. Phys. 1982, 76 (8), 39213927.

(54) Yamamoto, T.; Sawada, K. Molecular-Dynamics Simulation of Crystallization in Helical Polymers. J. Chem. Phys. 2005, 123 (23), 234906.

(55) Brandrup, J.; Immergut, E. H.; Grulike, E. A. Polymer Handbook; John Wiley \& Sons: New Jersey, 1999.

(56) Strobl, G. R. The Physics of Polymers: Concepts for Understanding Their Structures and Behavior, Springer-Verlag: Berlin, 2007.

(57) Flory, P. J. Statistical Thermodynamics of Semi-Flexible Chain Molecules. Proc. Roy. Soc. A 1956, 234 (1196) 60-73.

(58) Nitta, K. H-. On the Orientation-Induced Crystallization of Polymers. Polymers 2016, 8 (6), 229-241. 
for Table of Contents use only

\section{Investigation of the molecular mechanisms of melting and crystallization of isotactic polypropylene by in situ Raman spectroscopy}

Yusuke Hiejima, Kento Takeda, and Koh-hei Nitta
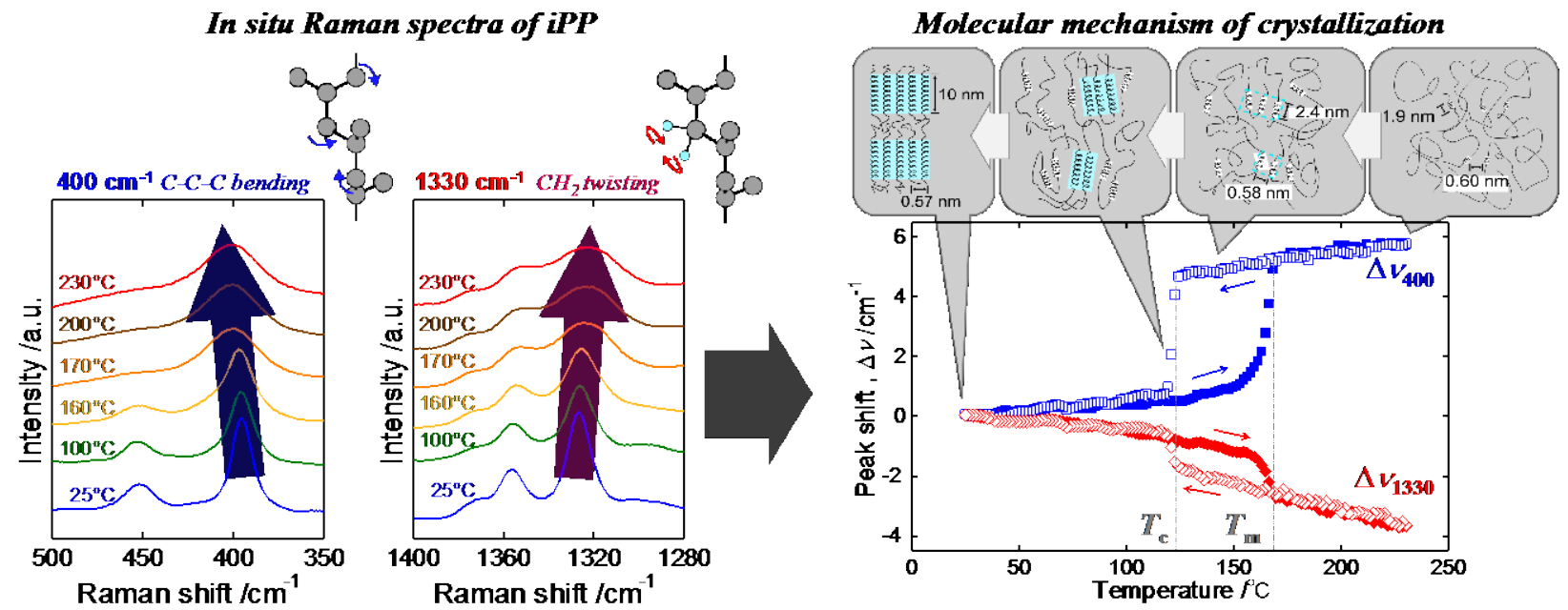